\title{
THE FUZZY IN EVERY PROCESS CONTROL SYSTEM
}

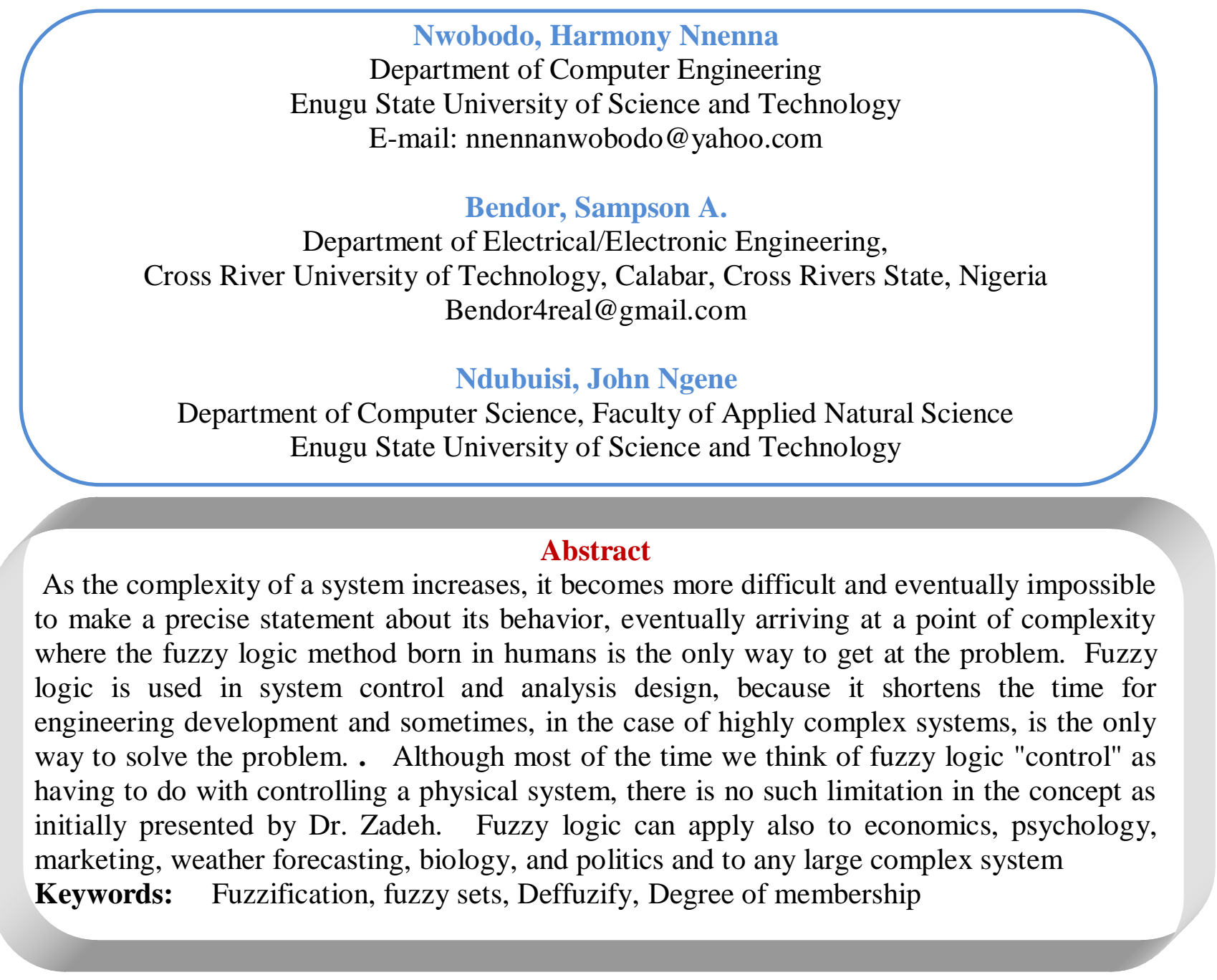

\section{Introduction}

Fuzzy logic is widely used in machine control. The term itself inspires a certain skepticism, sounding equivalent to "half-baked logic" or "bogus logic", but the "fuzzy" part does not refer to a lack of rigour in the method, rather to the fact that the logic involved can deal with fuzzy concepts - concepts that cannot be expressed as "true" or "false" but rather as "partially true". Although genetic algorithms and neural networks can perform just as well as fuzzy logic in many cases , fuzzy logic has the advantage that the solution to the problem can be cast in terms that human operators can understand, so that their experience can be used in the design of the controller. This makes it easier to mechanize tasks that are already successfully performed by humans.

\section{The Fuzzy Concept}

Fuzzy logic is not the wave of the future. It is now! There are already hundreds of millions of dollars of successful, fuzzy logic based commercial products, everything from selffocusing cameras to washing machines that adjust themselves according to how dirty the clothes are, automobile engine controls, anti-lock braking systems, color-film developing 
systems, subway control systems and computer programs trading successfully in the financial markets.

The objectives of this paper includes:

1. To introduce to individuals in the fields of business, industry, science, invention and dayto-day living the power and benefits available to them through the fuzzy logic method and to help them understand how fuzzy logic works.

2. To provide a fuzzy logic "how-to-do-it" guide, in terms everyone can understand, so everyone can put fuzzy logic to work doing something useful for them.

\section{Fuzzy Logic Analysis and Control}

Human beings have the ability to take in and evaluate all sorts of information from the physical world they are in contact with and to mentally analyze, average and summarize all this input data into an optimum course of action. All living things do this, but humans do it more and do it better and have become the dominant species of the planet.

If you think about it, much of the information you take in is not very precisely defined, such as evaluation of the behavior of a vehicle entering from a side street and the likelihood of the vehicle pulling in front of you. We call this fuzzy input. Your processing of all this information is not very precisely definable. We call this fuzzy processing. Fuzzy logic theorists would call it using fuzzy algorithm. Fuzzy logic is the way the human brain works, and we can mimic this in machines so they will perform somewhat like humans, not to be confused with Artificial Intelligence, where the so far unattainable goal is for machines to perform EXACTLY like humans.

Fuzzy logic control and analysis systems may be electro-mechanical in nature, or concerned only with data, for example economic data, in all cases guided by "If-Then rules" stated in human language.

\section{The Fuzzy Logic Method}

The fuzzy logic analysis and control method is, therefore:

1. Receiving of one, or a large number, of measurement or other assessment of conditions existing in some system we wish to analyze or control.

2. Processing all these inputs according to human based, fuzzy "If-Then" rules, which can be expressed in plain language words.

3. Averaging and weighting the resulting outputs from all the individual rules into one single output decision or signal which decides what to do or tells a controlled system what to do. The output signal eventually arrived at is a precise appearing, defuzzified, "crisp" value.

Below is the Fuzzy Logic Control/Analysis Method diagram:

\begin{tabular}{l|l|l} 
Input & $\begin{array}{l}\text { Processing } \\
\text { Determine action } \\
\text { to be taken } \\
\text { assessment of } \\
\text { based on human } \\
\text { determined fuzzy } \\
\begin{array}{l}\text { system conditions. } \\
\text { Examples: } \\
\text { temperature, } \\
\text { market data, } \\
\text { economic data. } \\
\text { combined with } \\
\text { non-fuzzy rules. }\end{array}\end{array}$
\end{tabular}

\section{The Fuzzy Logic Control-Analysis Method}




\section{Fuzzy Perception}

A fuzzy perception is an assessment of a physical condition that is not measured with precision, but is assigned an intuitive value. It will be seen below that fuzzy perceptions can serve as a basis for processing and analysis in a fuzzy logic control system.

Measured, non-fuzzy data is the input for the fuzzy logic method. Examples: temperature measured by a temperature transducer, motor speed, economic data, and financial markets data, etc. Then humans with their fuzzy perceptions and fuzzy rules take over. Human perceptions and rules are placed in-the-loop in the fuzzy logic based control system.

\section{Fuzzy Sets}

"Fuzzy sets" can be a complex mathematical term in multivalued logic. For our purposes in considering electro-mechanical systems control, a fuzzy set is an object with elements, or members, which can belong to it in degrees.

Examples of fuzzy sets are: motor speed, boiler pressure, shower-water temperature, etc. Too high motor speed, very low boiler pressure and hot shower water are sub-sets of the fuzzy sets.

\section{Assigning Zero to One Values to Fuzzy Sub-Sets}

A fuzzy control system is a control system based on fuzzy logic - a mathematical system that analyzes analog input values in terms of logical variables that take on continuous values between 0 and 1 , in contrast to classical or digital logic, which operates on discrete values of either 0 and 1 (true and false).

When implementing fuzzy logic control with human originated rules in the loop, we must have a way to assign some numeric value to humans' intuitive assessments of fuzzy sets. We must translate from human fuzziness to numbers that can be used by a computer. We do this by assigning fuzzy sub-set conditions a value from zero to 1.0. In setting up a control system for room temperature, for example, we could assign a membership of "1.0" in the sub-set of "just right" when the temperature is 75 degrees F. Then, if the temperature drops to 70 degrees F, we might design the system for a membership in the "just right" sub-set of ".8". Fuzzy logic makes use of human common sense. This common sense is either applied from what seems reasonable, for a new system, or from experience, for a system that has previously had a human operator.

The input variables in a fuzzy control system are in general mapped into by sets of membership functions similar to this, known as "fuzzy sets". The process of converting a crisp input value to a fuzzy value is called "fuzzification".

A control system may also have various types of switch, or "ON-OFF", inputs along with its analog inputs, and such switch inputs of course will always have a truth value equal to either 1 or 0 , but the scheme can deal with them as simplified fuzzy functions that happen to be either one value or another.

Given "mappings" of input variables into membership functions and truth values, the microcontroller then makes decisions for what action to take based on a set of "rules", each of the form:For instance,

IF brake temperature IS warm AND speed IS not very fast

THEN brake pressure IS slightly decreased.

In this example, the two input variables are "brake temperature" and "speed" that have values defined as fuzzy sets. The output variable, "brake pressure", is also defined by a fuzzy set that can have values like "static", "slightly increased", "slightly decreased", and so on. This rule by itself is very puzzling since it looks like it could be used without bothering with fuzzy logic, but remember the decision is based on a set of rules: 
- All the rules that apply are invoked, using the membership functions and truth values obtained from the inputs, to determine the result of the rule.

- This result in turn will be mapped into a membership function and truth value controlling the output variable.

- These results are combined to give a specific ("crisp") answer, the actual brake pressure, a procedure known as "defuzzification".

This combination of fuzzy operations and rule-based "inference" describes a "fuzzy expert system".

\section{Fuzzy control Design}

The design of fuzzy controllers consists of an input stage, a processing stage, and an output stage. The input stage maps sensor or other inputs, such as switches, thumbwheels, and so on, to the appropriate membership functions and truth values. The processing stage invokes each appropriate rule and generates a result for each, then combines the results of the rules. Finally, the output stage converts the combined result back into a specific control output value.

The most common shape of membership functions is triangular, although trapezoidal and bell curves are also used, but the shape is generally less important than the number of curves and their placement. From three to seven curves are generally appropriate to cover the required range of an input value, or the "universe of discourse" in fuzzy jargon.

As discussed earlier, the processing stage is based on a collection of logic rules in the form of IF-THEN statements, where the IF part is called the "antecedent" and the THEN part is called the "consequent". Typical fuzzy control systems have dozens of rules.

Consider a rule for a thermostat:

IF (temperature is "cold") THEN (heater is "high")

This rule uses the truth value of the "temperature" input, which is some truth value of "cold", to generate a result in the fuzzy set for the "heater" output, which is some value of "high". This result is used with the results of other rules to finally generate the crisp composite output. Obviously, the greater the truth value of "cold", the higher the truth value of "high", though this does not necessarily mean that the output itself will be set to "high", since this is only one rule among many. In some cases, the membership functions can be modified by "hedges" that are equivalent to adjectives. Common hedges include "about", "near", "close to", "approximately", "very", "slightly", "too", "extremely", and "somewhat". These operations may have precise definitions, though the definitions can vary considerably between different implementations. "Very", for one example, squares membership functions; since the membership values are always less than 1, this narrows the membership function. "Extremely" cubes the values to give greater narrowing, while "somewhat" broadens the function by taking the square root.

In practice, the fuzzy rule sets usually have several antecedents that are combined using fuzzy operators, such as AND, OR, and NOT, though again the definitions tend to vary: AND, in one popular definition, simply uses the minimum weight of all the antecedents, while OR uses the maximum value. There is also a NOT operator that subtracts a membership function from 1 to give the "complementary" function.

There are several different ways to define the result of a rule, but one of the most common and simplest is the "max-min" inference method, in which the output membership function is given the truth value generated by the premise.

Rules can be solved in parallel in hardware, or sequentially in software. The results of all the rules that have fired are "defuzzified" to a crisp value by one of several methods. There are dozens in theory, each with various advantages and drawbacks. 
The "centroid" method is very popular, in which the "center of mass" of the result provides the crisp value. Another approach is the "height" method, which takes the value of the biggest contributor. The centroid method favors the rule with the output of greatest area, while the height method obviously favors the rule with the greatest output value.

The diagram below demonstrates max-min inferencing and centroid defuzzification for a system with input variables "x", "y", and "z" and an output variable "n". Note that "mu" is standard fuzzy-logic nomenclature for "truth value":

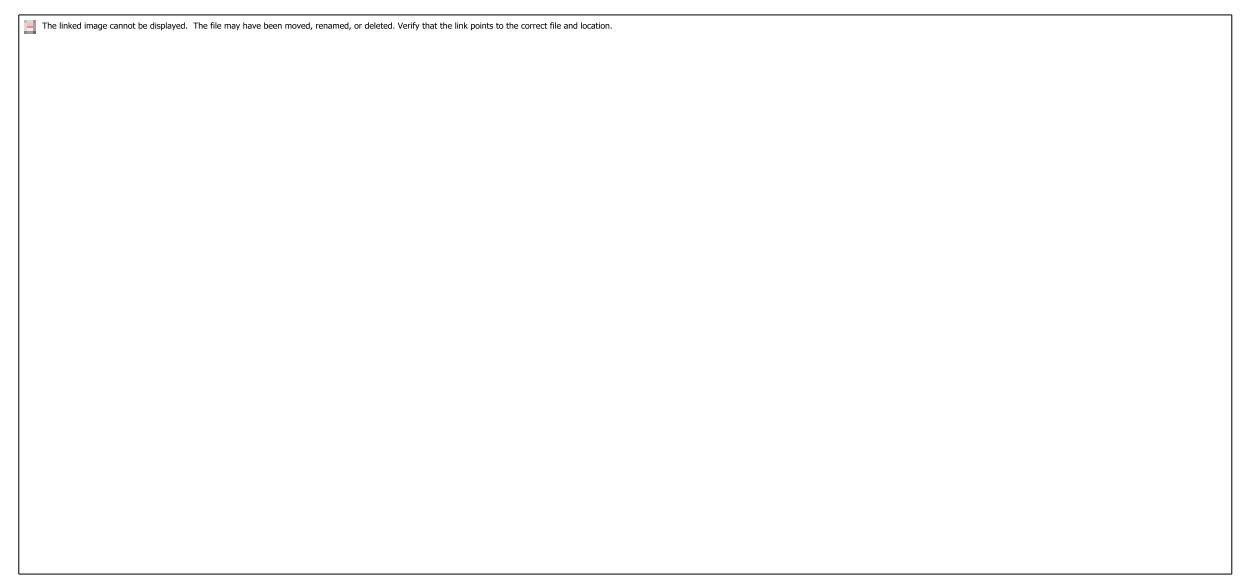

Notice how each rule provides a result as a truth value of a particular membership function for the output variable. In centroid defuzzification the values are OR'd, that is, the maximum value is used and values are not added, and the results are then combined using a centroid calculation.

Fuzzy control system design is based on empirical methods, basically a methodical approach to trial-and-error. The general process is as follows:

- Document the system's operational specifications and inputs and outputs.

- Document the fuzzy sets for the inputs.

- Document the rule set.

- Determine the defuzzification method.

- Run through test suite to validate system, adjust details as required.

- Complete document and release to production.

\section{CONTINUOUS CONTROL OF WATER LEVEL OF A TANK Inflow}

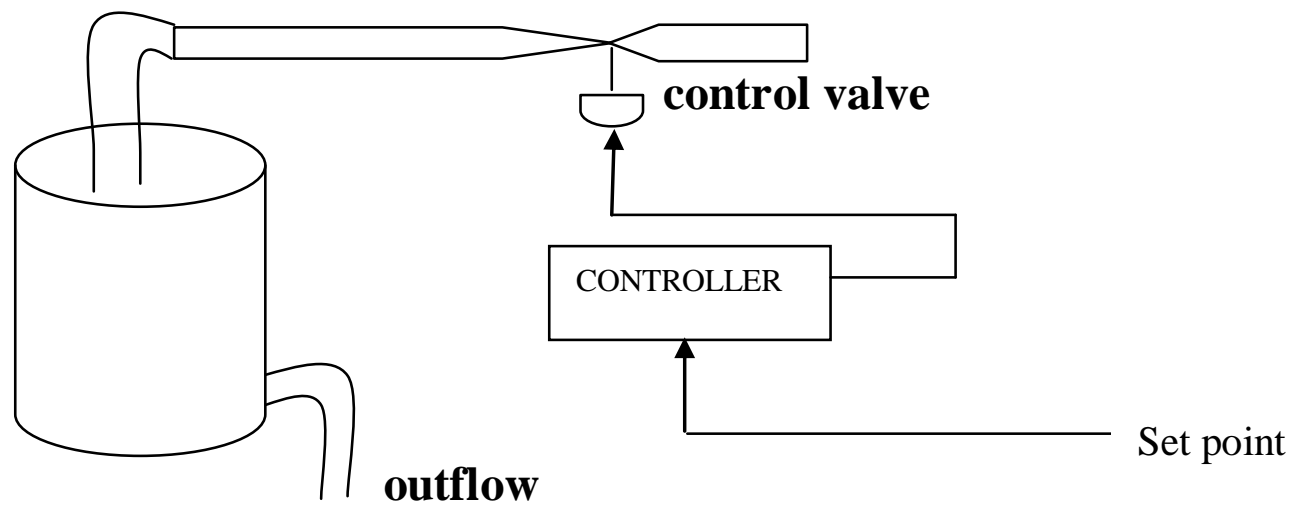

Figure A: Tank Water Level control 
The figure A above shows a tank with a valve that controls flow of liquid into the tank and some unspecified flow out of the tank. A transducer is available to measure the level of liquid in the tank. There is also a control system whose objective is to maintain the level of liquid in the tank at some preset or set point value.

The controller will operate according to some mode of control to maintain the level against variations induced from external influences.

Thus, if the outflow increases, the control system will increase the opening of the input value to compensate by increasing the input flow rate.

\section{HOW IT WORKS}

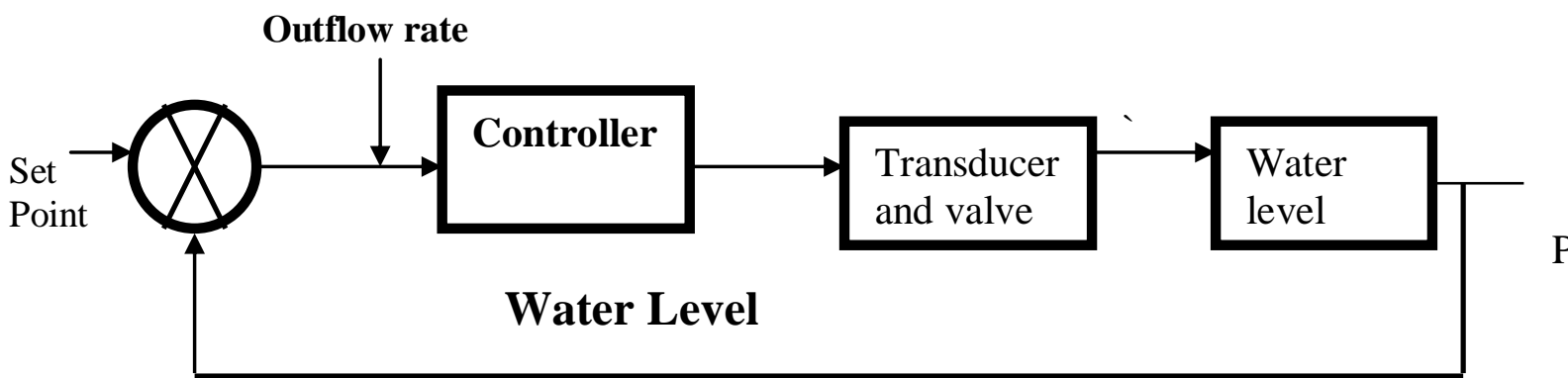

The liquid is at set point $(r)$, the water level $( \pm b)$ is to be compared with the liquid at its setpoint to monitor the deviation (e), which determines the outflow rate, and hence the controller now determines the action of value controlled by the transducer which now affects the height of the water level.

THE FUZZY CONTROLLER OF THE TANK WATER LEVEL

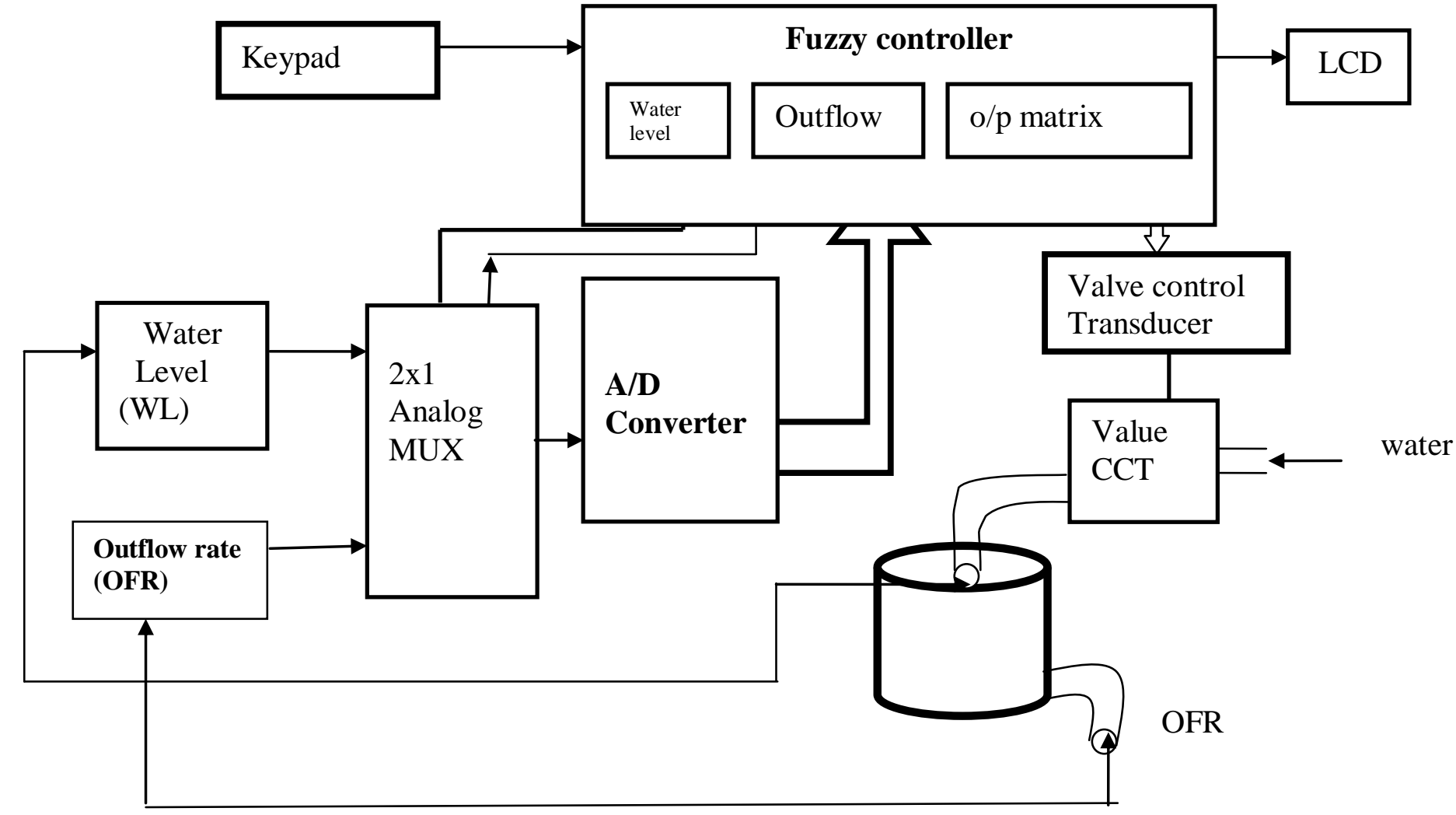


To determine the fuzzy rule set. The values is defined as follows

\begin{tabular}{|c|c|c|c|}
\hline Vw & - & Very Wide & \\
\hline W & - & wide & \\
\hline $\mathrm{Nm}$ & - & Normal & \\
\hline $\mathrm{Na}$ & - & Narrow & \\
\hline $\mathrm{VNa}$ & - & Very Narrow & 1 \\
\hline
\end{tabular}

The outflow rate is defined as

$\begin{array}{lll}\mathrm{VH} & - & \text { Very High } \\ \mathrm{H} & - & \text { High } \\ \mathrm{N} & - & \text { Normal } \\ \mathrm{N} & - & \text { Low } \\ \mathrm{VL} & - & \text { very low }\end{array}$

The change in liquid level with reference to the set point is defined as

$\begin{array}{lllr}\mathrm{H}_{5} & - & \text { Very high } & 12 \\ \mathrm{H}_{4} & - & \text { High } & 11 \\ \mathrm{H}_{3} & - & \text { Zero (at set point) } & 10 \\ \mathrm{H}_{2} & - & \text { low } & 9 \\ \mathrm{H}_{1} & - & \text { very Low } & 8\end{array}$

The rule sets for the water level are as this

$\begin{array}{lll}\text { Rout } & = & \text { rate of outflow } \\ \mathrm{dL} & = & \text { change in water level } \\ \mathrm{V}_{\mathrm{o}} & = & \text { valve setting }\end{array}$

\begin{tabular}{|c|c|c|}
\hline RULE & CONDITION & ANTECEDENT \\
\hline 1. & If Rout is $\mathrm{V}_{\mathrm{H}}$ AND dl is $\mathrm{H}_{5}$ & THEN $V_{o}$ is $N_{m}$ \\
\hline 2. & If Rout is $\mathrm{V}_{\mathrm{H}}$ AND dl is $\mathrm{H}_{5}$ & THEN $\mathrm{V}_{\mathrm{o}}$ is $\mathrm{N}_{\mathrm{a}}$ \\
\hline 3. & If Rout is $\mathrm{V}_{\mathrm{N}}$ AND dl is $\mathrm{H}_{5}$ & THEN $V_{o}$ is $N_{a}$ \\
\hline 4 & If Rout is L AND dl is $\mathrm{H}_{5}$ & THEN $V_{o}$ is $V_{N a}$ \\
\hline 5 & If Rout is $\mathrm{V}_{\mathrm{L}} \mathrm{AND} \mathrm{dl}$ is $\mathrm{H}_{5}$ & THEN $V_{0}$ is $V_{N a}$ \\
\hline 6 & If Rout is $\mathrm{V}_{\mathrm{H}}$ AND dl is $\mathrm{H}_{4}$ & THEN $V_{o}$ is $N_{m}$ \\
\hline 7 & If Rout is $\mathrm{H}$ AND dl is $\mathrm{H}_{4}$ & THEN $V_{o}$ is $N_{m}$ \\
\hline 8 & If Rout is $\mathrm{N}$ AND dl is $\mathrm{H}_{4}$ & THEN $\mathrm{V}_{\mathrm{o}}$ is $\mathrm{N}_{\mathrm{a}}$ \\
\hline 9. & If Rout is $\mathrm{L}$ AND dl is $\mathrm{H}_{4}$ & THEN $V_{o}$ is $V_{\text {ma }}$ \\
\hline 10 & If Rout is VL AND dl is $\mathrm{H}_{4}$ & THEN $V_{0}$ is $V_{\mathrm{Na}}$ \\
\hline 11 & If Rout is $\mathrm{V}_{\mathrm{H}}$ AND $\mathrm{dl}$ is $\mathrm{H}_{3}$ & THEN $\mathrm{V}_{\mathrm{o}}$ is $\mathrm{V}_{\mathrm{m}}$ \\
\hline 12 & If Rout is $\mathrm{H}$ AND $\mathrm{dl}$ is $\mathrm{H}_{3}$ & THEN $\mathrm{V}_{\mathrm{o}}$ is $\mathrm{W}$ \\
\hline 13 & If Rout is N AND dl is $\mathrm{H}_{3}$ & THEN $V_{o}$ is $N_{m}$ \\
\hline 14 & If Rout is L AND dl is $\mathrm{H}_{3}$ & THEN V $_{\mathrm{o}}$ is $\mathrm{N}_{\mathrm{a}}$ \\
\hline 15 & If Rout is $\mathrm{V}_{\mathrm{L}}$ AND dl is $\mathrm{H}_{3}$ & THEN $V_{0}$ is $V_{N a}$ \\
\hline 16 & If Rout is $\mathrm{V}_{\mathrm{H}}$ AND dl is $\mathrm{H}_{2}$ & THEN $V_{o}$ is $V_{w}$ \\
\hline 17 & If Rout is $\mathrm{H}$ AND dl is $\mathrm{H}_{2}$ & THEN $V_{o}$ is $\mathrm{W}$ \\
\hline 18 & If Rout is N AND dl is $\mathrm{H}_{2}$ & THEN $\mathrm{V}_{\mathrm{o}}$ is $\mathrm{W}$ \\
\hline 19 & If Rout is L AND dl is $\mathrm{H}_{2}$ & THEN $V_{o}$ is $N_{a}$ \\
\hline 20 & If Rout is $\mathrm{V}_{\mathrm{L}}$ AND $\mathrm{dl}$ is $\mathrm{H}_{2}$ & THEN $V_{o}$ is $N_{m}$ \\
\hline 21 & If Rout is $\mathrm{V}_{\mathrm{H}}$ AND dl is $\mathrm{H}_{1}$ & THEN $V_{o}$ is $V_{m}$ \\
\hline 22 & If Rout is $\mathrm{H}$ AND dl is $\mathrm{H}_{1}$ & THEN $V_{o}$ is $V_{w}$ \\
\hline 23 & If Rout is N AND dl is $\mathrm{H}_{1}$ & THEN $\mathrm{V}_{\mathrm{o}}$ is $\mathrm{W}$ \\
\hline 24. & If Rout is $\mathrm{L} \mathrm{AND} \mathrm{dl}$ is $\mathrm{H}_{1}$ & THEN $\mathrm{V}_{\mathrm{o}}$ is $\mathrm{W}$ \\
\hline 25 & If Rout is $\mathrm{V}_{\mathrm{L}}$ AND $\mathrm{dl}$ is $\mathrm{H}_{1}$ & THEN $V_{0}$ is $\mathrm{W}$ \\
\hline
\end{tabular}




\section{The fuzzy matrix is shown below}

\begin{tabular}{|l|l|l|l|l|l|}
\hline DI Rout & $\mathbf{V}_{\mathbf{H}}$ & $\mathbf{H}$ & $\mathbf{N}$ & $\mathbf{L}$ & $\mathbf{V}_{\mathbf{L}}$ \\
\hline $\mathrm{H}_{5}$ & $\mathbf{N}_{\mathbf{m}}$ & $\mathbf{N a}$ & $\mathbf{N a}$ & $\mathbf{V}_{\mathbf{N a}}$ & $\mathbf{V}_{\mathbf{N a}}$ \\
\hline $\mathrm{H}_{4}$ & $\mathbf{N}_{\mathbf{m}}$ & $\mathbf{N}_{\mathbf{m}}$ & $\mathbf{N a}$ & $\mathbf{V}_{\mathbf{N a}}$ & $\mathbf{V}_{\mathbf{N a}}$ \\
\hline $\mathrm{H}_{3}$ & $\mathbf{V}_{\mathbf{w}}$ & $\mathbf{W}$ & $\mathbf{N}_{\mathbf{m}}$ & $\mathbf{N}_{\mathbf{a}}$ & $\mathbf{V}_{\mathbf{N a}}$ \\
\hline $\mathrm{H}_{2}$ & $\mathbf{V}_{\mathbf{w}}$ & $\mathbf{W}$ & $\mathbf{W}$ & $\mathbf{\mathbf { N } _ { \mathbf { a } }}$ & $\mathbf{N}_{\mathbf{m}}$ \\
\hline $\mathrm{H}_{1}$ & $\mathbf{V}_{\mathbf{w}}$ & $\mathbf{V}_{\mathbf{W}}$ & $\mathbf{W}$ & $\mathbf{W}$ & $\mathbf{W}$ \\
\hline
\end{tabular}

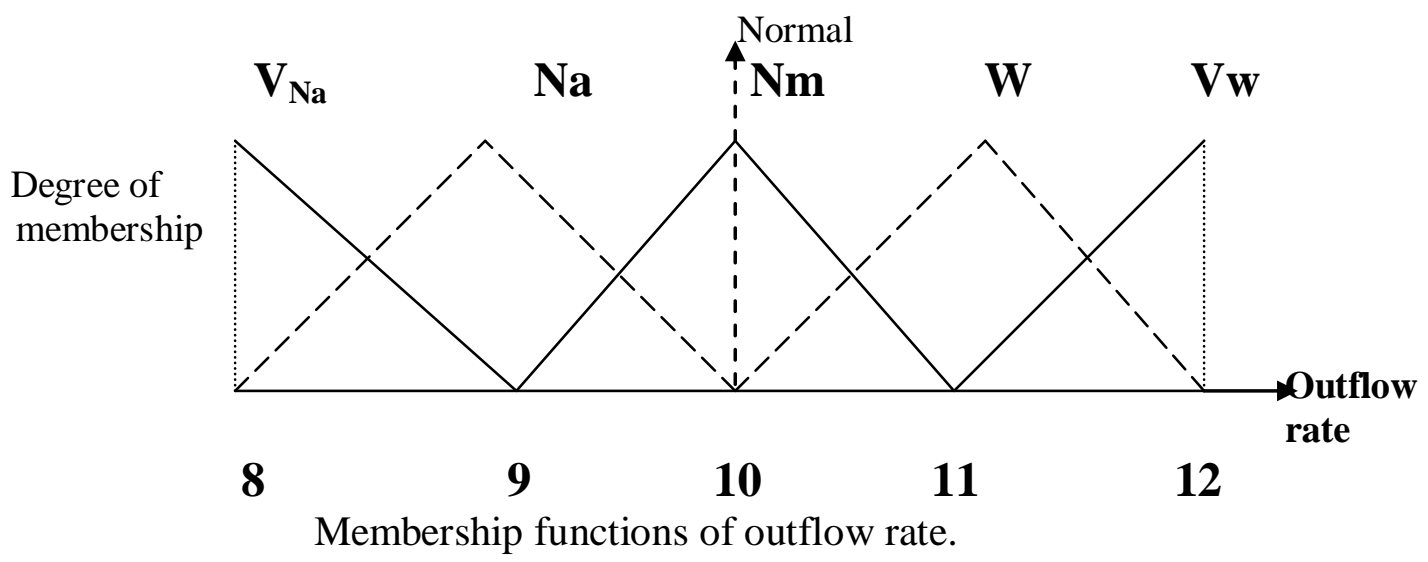

Normal

Degree of membersip

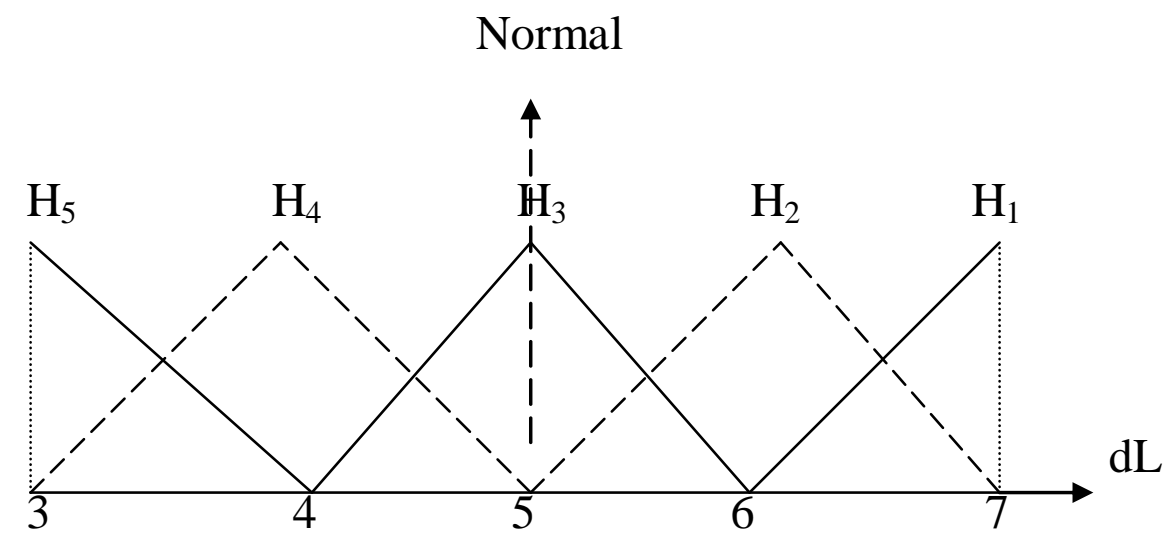

Membership functions of the change in liquid level.

Degree of membership

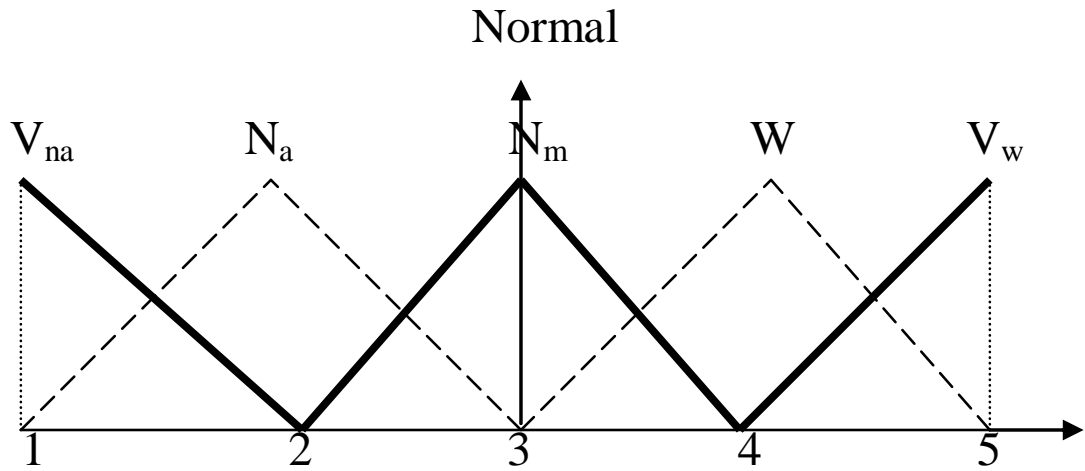

Membership functions of the valve setting. 


\section{Conclusion}

This paper shows that as the complexity of a system increases, it becomes more difficult and eventually impossible to make a precise statement about its behavior, eventually arriving at a point of complexity or ambiguity (showing fuzzy) where the fuzzy logic method born in humans is the only way to get at the problem. Techniques on the fuzzy control design are also shown.

\section{Acknowledgement}

This paper was developed within the generous framework offered by Dr. Lotfi Zadeh and E.H. Mamdani on fuzzy logic.

\section{References}

1) Zadeh, L.A, "Fuzzy sets", Information and control, Vol. 8 1965, pp.338-353

2) Gerla G., Fuzzy Logic Programming and fuzzy control, Studia Logica, 79 (2005) 231-254.

3) Mamdani, E. H., Application of fuzzy algorithms for the control of a simple dynamic plant. In Proc IEEE (1974), 121-159.

4) Jan Jantzen, Foundations of Fuzzy Control. Wiley, 2007 (209 page) 